\title{
"Appropriateness and adequacy of antibiotic prescription for upper respiratory tract infections in ambulatory health care centers in Ecuador"
}

\author{
Xavier Sánchez Choez ${ }^{1,2^{*}}$ (D) María Luciana Armijos Acurio ${ }^{1}$ and Ruth E. Jimbo Sotomayor ${ }^{1,2}$
}

\begin{abstract}
Background: Upper respiratory tract infections are the leading cause of misuse of antibiotics, a problem that leads to unnecessary adverse events and antibiotic resistance. Antibiotic prescription in Ecuador was analyzed in order to evaluate the state of antibiotic prescribing for upper respiratory tract infections. Both the appropriateness and adequacy of prescribing was evaluated. Appropriateness represents the percentage of prescriptions that are indicated; adequacy refers to the percentage of patients requiring antibiotics who are treated.
\end{abstract}

Methods: The aim of the study is to analyze the appropriateness and adequacy of antibiotic prescription for upper respiratory tract infections in the Ambulatory Health Centers of the Ministry of Public Health of Ecuador. This is a cross-sectional study of patients from one Health Center of the Ministry of Public Health in the District 17D03 in Ecuador during 2015 with upper respiratory tract infection as a primary diagnosis.

Results: We included a total of 1393 patients in the analysis. Out of the 1393 patients identified, 523 were prescribed antibiotics, constituting an antibiotic prescription rate of $37.5 \%$, and 51 required antibiotics, reflecting a real need of antibiotics of 3.7\%. Appropriateness: Of these 523 patients who were treated, 51 required an antibiotic, resulting in an appropriate antibiotic prescription rate of 9.75\%. Adequacy: When analyzing each individual case, 33 of these 51 patients received an antibiotic, constituting an adequate prescription rate of $64.7 \%$.

Conclusions: The results of our study report a $90.25 \%$ of inappropriate prescription. The antibiotic prescription, appropriate prescription, and adequate prescription rates show the need for implementation of strategies in order to reduce them. Related aspects regarding prescriber's behavior and the patient's expectations should be analyzed.

Keywords: Antibiotic, Prescription, Family practice, Health systems and services, Anti-bacterial agents, Drug utilization, Practice guidelines

\section{Background}

Appropriate and adequate use of drugs is now one of the most commonly debated topics in public health. According to the $\mathrm{WHO}$, only $50 \%$ of all prescribed medications are dispensed or sold in an appropriate way [1]. On the other hand, about one third of the world population lacks access to drugs considered as essential drugs by the WHO [2]. According to the

\footnotetext{
* Correspondence: xavier.sanchez.c@gmail.com

${ }^{1}$ Pontificia Universidad Católica del Ecuador, Posgrado de Medicina Familiar,

Avenida 12 de Octubre 1076, Vicente Ramón Roca, Quito, Ecuador

${ }^{2}$ Universidad Alcalá de Henares, Alcalá de Henares, Spain
}

WHO, the rational use of drugs requires that "patients receive medications appropriate to their clinical needs, in doses that meet their own individual requirements, for an adequate period of time, and at the lowest cost to them and their community" [3]. The appropriate prescription rate is the number of cases that need treatment divided by the number of cases that receive it. It has the objective of maximizing the effectiveness of a treatment, minimizing the risk and costs, and taking into consideration the preference of the patients [4]. Adequate prescription rate is the number of cases that needs and receives

(c) The Author(s). 2018 Open Access This article is distributed under the terms of the Creative Commons Attribution 4.0 International License (http://creativecommons.org/licenses/by/4.0/), which permits unrestricted use, distribution, and 
treatment divided by the number of cases that need it. Adequate prescription allows us to analyze if patients that require treatment are receiving it.

Differences in prescription can be due to both the prescriber and the patient. Studies have shown that factors like gender, multi-morbidity and previous personal experiences can influence prescription $[5,6]$. Prescription is also influenced by the health provider's knowledge of evidence based medicine, current guidelines, personal experience and lack of time or availability of drugs [7].

A 2016 study by Fleming-Dutra et al. in the United States shows a rate of inappropriate oral antibiotic prescription of about $50 \%$ in upper respiratory tract infection (URTI), adjusted by age and diagnostic in adults and children [8]. Another study in children in France finds results that suggest a $76 \%$ rate of inappropriate prescription of antibiotics for any pediatric diagnosis in primary health care and that URTI are the leading cause of misuse of antibiotics. [9].

A prospective study with 3402 patients with acute cough from 13 European countries analyzed the variation in prescription of antibiotics in primary care. Their results showed a high prescription rate, in all countries included that ranged between 20 and 90\% (media of 53\%) [10]. Another study from four Latin American countries found that $33 \%$ of patients with a suspicion of URTI in primary care centers that were included in the study were prescribed antibiotics [11].

Even though resistance to antibiotics is a natural phenomenon in bacteria, human activities have potentiated its expansion, favoring the appearance of resistant strains. The lack of efficient practices for prevention and control of infections has also contributed to the emergence of new resistances [12]. The inappropriate use of antimicrobials increases the risk of drug-resistant microorganisms [13]

Costelloe, et al. in 2010, demonstrate a strong association between the prescription of antibiotics in primary care and antimicrobial resistance in URTI [14]. It has been reported that antibiotic resistance to microorganisms such as Staphylococcus aureus, enterococci, and gram-negative bacilli, are associated with an increase in mortality, morbidity, days of hospitalization and health costs [15]. The increase in health costs associated to antibiotic resistance is due to the longer duration of disease and the need for additional diagnostic tests and high-cost antibiotics. [16].

Due to the large impact on health, antibiotic prescription in Ecuador was analyzed in order to evaluate if the tendency aligns with the misuse of antibiotics occurring around the world. Defining the scope of the problem will allow for further analysis and policy implementation in the country.

\section{Methods}

The aim of this study was to analyze the appropriateness and adequacy of antibiotic prescription for URTI in the Ambulatory Health Centers of the Ministry of Public Health of Ecuador in the District 17D03 during 2015. The design of this cross-sectional study of the appropriateness and adequacy of antibiotic prescription imitates similar studies from different settings [8, 17-19] allowing us to obtain comparable results. We considered "Appropriate prescription rate" as the number of appropriate antibiotic prescriptions divided by all patients receiving antibiotics. Our definition of "Adequate prescription rate" is the number of patients that need and receive antibiotics divided by the number of patients that need it. The purpose of measuring the appropriate prescription rate is to identify the over-prescription that could be occurring. On the other hand, the purpose of analyzing the "Adequate prescription rate" is to identify cases of patients that needed antibiotics and did not receive treatment.

\section{Data source}

The data source for the variables included in this study are the Electronic Health Records (EHR) of all the patients from one Health Center of the Ministry of Public Health in the District 17D03 in Ecuador during 2015 with URTI as a primary diagnosis. This district has been using EHR since 2010. Prescribers enter the information directly into the EHR on a computer during the outpatient appointment. Information was manually extracted from the EHR simultaneously by two peer reviewers, according to the following criteria:

Inclusion criteria: Patients 3 months of age and above who required clinical care for URTI in the Ambulatory Health Centers of the Ministry of Public Health in the District 17D03 in 2015.

Exclusion criteria: 1) Patients who received clinical care in the ambulatory health centers of the Ministry of Public Health that are not a part of the D1703 district; 2) Patients who received clinical care in ambulatory health centers that are not a part of the Ministry of Public Health in the D1703 district.

The International Classification of Disease (ICD) - 10 was used for selection of the diagnosis criteria for URTI, where we considered codes J00-J06, J10, J11, H65, H66 (Table 1). After individual data extraction, information was compared, and reached a consensus of inclusion or exclusion for each patient. An additional text file of description of variables shows the variables collected for the analysis of appropriateness and adequacy of antibiotic prescription (see Additional file 1).

The patients included in this study were those attended by the 5 types of health professionals that work in the designated health center and that diagnosed 
Table 1 ICD-10 Codes considered as "upper respiratory tract infections" for the purpose of this study

We considered an upper respiratory tract infection diagnosis as any diagnosis registered according to the ICD-10 classification, as any the following:

- JOO Acute nasopharyngitis [common cold]

- JO1 Acute sinusitis (includes J01.0, J01.1, J01.2, J01.3, J01.4, J01.8, J01.9)

- JO2 Acute pharyngitis (includes J02.0, J02.8, J02.9)

- JO3 Acute tonsillitis (includes J03.0, J03.8, J03.9)

- J04 Acute laryngitis and tracheitis (includes J04.0, J04.1, J04.2)

- JO5 Acute obstructive laryngitis [croup] and epiglottitis

- JO6 Acute upper respiratory infections of multiple and unspecified sites (includes J06.0, J06.8, J06.9)

- J10 Influenza due to other identified influenza virus (includes J10.1)

- J11 Influenza due to unidentified influenza virus (includes J11.1) We will consider as part of the upper respiratory tract infections, diseases of the middle ear categorized according to ICD-10 as:

- H65 Nonsuppurative otitis media

- H66 Suppurative and nonspecified otitis media

patients with URTI. These health professionals are classified as:

- Rural Medical Trainees: Medical Doctor that has recently completed their degree and is performing a year of community service as a health professional in a rural location as a prerequisite for medical practice in Ecuador.

- General Practitioner: Medical Doctor that has completed the year of community service as a health professional and can practice medicine freely in Ecuador.
- Family Medicine Doctor: Medical Doctor that has performed a postgraduate degree of 3 years in General Practice and is considered a specialist in Ecuador.

- Psychiatrists: Medical Doctor that has performed a postgraduate degree of 3 years in Psychiatry and is considered a specialist in Ecuador.

- Pediatricians: Medical Doctor that has performed a postgraduate degree of 3-4 years in Pediatrics and is considered a specialist in Ecuador.

\section{Sample}

The sample was defined as all the patients that met the inclusion criteria and that had complete information in their EHR. Our sample is of 1393 patients.

\section{Assessment of appropriateness and adequacy of antibiotic prescription}

For this study, "Appropriate antibiotic prescription" is considered according to the standards defined in the Clinical Guideline for "Respiratory Tract Infections (self-limiting): prescribing antibiotics CG69" by the National Institute for Health and Care Excellence (NICE), considering the lack of a National clinical guideline for URTI in Ecuador. Table 2 describes the criteria for cases that needed antibiotic prescription according to each ICD category, as described in the NICE Clinical Guideline. Need for antibiotics was assessed by two reviewers separately in order to identify the cases that met the

Table 2 Guide for Classifying Appropriate Antibiotic Prescription: using ICD-10 codes to classify appropriate diagnosis of disease according to the symptoms and signs presented in the patients in the sample

\begin{tabular}{|c|c|}
\hline ICD-10 code & Criteria for Appropriate Antibiotic Prescription \\
\hline $\begin{array}{l}\text { H65 Nonsuppurative otitis media } \\
\text { H66 Suppurative and nonspecified otitis media }\end{array}$ & $\begin{array}{l}\text { H65 must meet both conditions: presence of Acute Bilateral Otitis media AND age }<2 \\
\text { H65 or H66 with presence of otorrhea }\end{array}$ \\
\hline J01 Acute sinusitis & Must meet all conditions: Fever of $>38 \mathrm{C}^{\circ}$, purulent discharge and facial pain \\
\hline $\begin{array}{l}\text { JO2 Acute pharyngitis } \\
\text { JO3 Acute tonsillitis }\end{array}$ & $\begin{array}{l}\text { Must meet } 3 \text { of the following CENTOR criteria: } \\
\text { Presence of tonsilar exudate } \\
\text { Presence of painful anterior cervical lymphadenopathy or lymphadenitis } \\
\text { Fever }\left(>38^{\circ}\right) \\
\text { Absence of cough }\end{array}$ \\
\hline $\begin{array}{l}\text { JOO Acute nasopharyngitis [common cold] } \\
\text { JO1 Acute sinusitis } \\
\text { JO2 Acute pharyngitis } \\
\text { JO3 Acute tonsillitis } \\
\text { JO4 Acute laryngitis and tracheitis } \\
\text { JO5 Acute obstructive laryngitis [croup] and } \\
\text { epiglotitis } \\
\text { JO6 Acute upper respiratory infections of } \\
\text { multiple and unspecified sites } \\
\text { J10 Influenza due to other identified influenza } \\
\text { virus } \\
\text { J11 Influenza due to unidentified influenza virus }\end{array}$ & $\begin{array}{l}\text { Must meet any of the following criteria: } \\
\text { Presence of one or more of the following comorbidities: Cardiac, Pulmonary, Renal, Hepatic, } \\
\text { Neuromuscular, Immunosuppression, Cystic Fibrosis, Diabetes Mellitus. } \\
\text { - OR } \\
\text { Age }<2 \text { years old AND history of prematurity } \\
\text { OR } \\
\text { Age }>65 \text { years old AND presence of cough AND two or more of the following: } \\
\text { - Hospitalized in } 2014 \\
\text { - Diabetes mellitus } \\
\text { - History of cardiac arrest } \\
\text { - Current use of corticosteroids } \\
\text { OR } \\
\text { Age }>80 \text { years old AND presence of cough AND one or more of the following: } \\
\text { - Hospitalized in } 2014 \\
\text { - Diabetes mellitus } \\
\text { - History of cardiac arrest } \\
\text { - Current use of corticosteroids }\end{array}$ \\
\hline
\end{tabular}


criteria for antibiotic prescription. When a data inconsistency was found in the EHR, the agreement was reached by consensus by the reviewers. We assessed appropriateness of the prescription by identifying the cases that needed treatment divided by the number of cases that received it. We assessed adequacy of the prescription by identifying individual patients that required antibiotic treatment according to Table 2 and evaluated if they received it or not.

The antibiotic prescription rate was defined as the number of antibiotic prescriptions divided by all patients diagnosed with URTI.

\section{Statistical analysis}

The variables included in this study were qualitative dichotomous and categorical variables and quantitative continuous variables, an additional text file of description of variables shows this in more detail (see Additional file 1). We performed a descriptive analysis with qualitative variables through frequency distributions, proportions and rates; and of quantitative variables through measures of central tendency and dispersion. We then performed statistical tests to determine the association between antibiotic prescription and several variables through a logistic regression. This regression analyzes the relationship between a dependent variable, antibiotic prescription, and independent variables, controlling for potential confounders. The independent variables were chosen by theoretical relationship to the dependent variable and through bivariate logistic regression models, an additional text file of variables considered for the regression models shows this in more detail (see Additional file 2). In the model we only included variables with a $p$ value of $<0.25$. These variables were: gender of prescriber, hours dedicated to clinical practice and category of health professionals. We excluded patient age, prescriber age and gender of patient due to their lack of statistical significance.

For the only categorical variable included, category of health professionals, we analyzed each category and decided to exclude Psychiatrists, due to the low number of consults included in the data. Then we reintroduced some variables that according to literature could be potential confounders (prescriber age and patient age) one by one creating an extended model, but did not find anything of significance. In order to choose between the models to be used, we used Akaike's Information Criteria (AIC). The formula for the final model was:

\section{Log(antibiotic prescription) $=$ b0 + b $1 *$ i.levelhp_cate + b2*gender_prescriber + b3*hours_clinical}

Where i.levlehp_cate is health professional categorized by type, gender_prescriber is the gender of the prescriber, and hours_clinical is the hours dedicated to clinical practice.
We used STATA v14 and Microsoft Excel as statistical software.

\section{Adequacy of dosage and duration of prescription of antibiotics}

We analyzed adequate dosage of antibiotics based on several clinical Guidelines defined in Table 3 [20-25]. This analysis consisted in categorizing prescriptions in those that were under the recommended dose, over the recommended dose, and adequate dose. We also analyzed the number of prescriptions that met the recommended amount of days of treatment. We considered 7 to 10 days as the adequate duration of treatment for all antibiotics included, except for Azithromycin and Penicillin benzathine. We considered 5 days as an adequate duration of treatment for Azithromycin and a single dose for Benzathine penicillin. To define the duration of treatment we used the same clinical guidelines used for the definition of adequate dosage. This analysis was done for each prescription in the patients included in this study.

\section{Results}

The general characteristics of our sample are described in Table 4.

\section{Adequacy and appropriateness of antibiotic prescription}

We included 1393 patients that met our inclusion criteria in the analysis that were attended by 21 health professionals (4 Rural Trainees, 7 General Practitioners, 6 Family Medicine Doctors, 3 Pediatricians and 1 Psychiatrist). Out of the 1393 patients, 523 were prescribed antibiotics, constituting an antibiotic prescription rate of $37.5 \%$. Of these 523 patients, 51 required an antibiotic, resulting in an appropriate antibiotic prescription rate of $9.75 \%$. The 51 patients in our sample that needed antibiotics represent $3.66 \%$ of all patients. When analyzing each individual case, 33 of these 51 patients received an antibiotic, constituting an adequate prescription rate of $64.7 \%$. We then debriefed the data by different diagnosis according to the ICD-10 codes (Table 5). Acute nasopharyngitis (J00), also known as common cold, represents $41.73 \%$ of all diagnoses. Only $2.41 \%$ of the cases of common cold had other criteria requiring antibiotics and $2.91 \%$ of the cases received antibiotics. Nevertheless, of the cases of J00 that needed antibiotics, only $5.88 \%$ received them, the rest of antibiotics prescribed were for cases where it was not needed. This scenario is very different when analyzing prescription for J02, J03 or J06. The results for J02 show us that $51.3 \%$ of patients with this diagnosis were prescribed antibiotics, when only $2.94 \%$ needed them. The case for acute tonsillitis (J03) is that $83.13 \%$ of the cases were prescribed antibiotics, when $9.64 \%$ needed them. For Acute upper respiratory infections of multiple and unspecified sites (J06) 61.5\% 
Table 3 Antibiotic Regimens Recommended for URTI

\begin{tabular}{|c|c|c|}
\hline Antibiotic & Dose & Reference \\
\hline Amoxicillin & $\begin{array}{l}\text { Pediatric: } 50 \mathrm{mg} / \mathrm{kg} \text { once daily or } 25 \mathrm{mg} / \mathrm{kg} \text { twice daily, } \\
\text { High dose } 80-90 \mathrm{mg} / \mathrm{kg} \text { in } 2 \text { divided doses (acute otitis media/acute bacterial sinusitis) } \\
\text { Adult: } 500 \mathrm{mg}-2000 \mathrm{mg} \text { twice daily }\end{array}$ & {$[20,21]$} \\
\hline Cephalexin & $\begin{array}{l}\text { Pediatric: } 20 \text { mg/kg/dose twice daily* } \\
\text { Adult:500 mg twice daily }\end{array}$ & {$[20,21]$} \\
\hline Benzathine Penicillin G & $\begin{array}{l}\text { Pediatric: < } 27 \mathrm{~kg}: 600000 \mathrm{U} ; \geq 27 \mathrm{~kg}: 1200000 \mathrm{U} \text { single dose } \\
\text { Adult: } 1200000 \cup \text { single dose }\end{array}$ & {$[20,21]$} \\
\hline Clarithromycin & $\begin{array}{l}\text { Pediatric: } 7.5 \mathrm{mg} / \mathrm{kg} / \text { dose twice daily } \\
\text { Adult: } 500 \mathrm{mg} \text { twice daily }\end{array}$ & {$[20,21]$} \\
\hline Azithromycin & $\begin{array}{l}\text { Pediatric: } 12 \mathrm{mg} / \mathrm{kg} \text { once daily } \\
\text { Adult: } 500 \mathrm{mg} \text { daily }\end{array}$ & {$[20,21]$} \\
\hline Erythromycin & $\begin{array}{l}\text { Pediatric: } 50 \mathrm{mg} / \mathrm{Kg} \text { divided four times } \\
\text { Adult: } 500 \mathrm{mg}\end{array}$ & {$[24,25]$} \\
\hline
\end{tabular}

Table 4 Characteristics of the sample

\begin{tabular}{|c|c|}
\hline Prescriber & $N(\%)$ \\
\hline Total of prescribers & $21(100 \%)$ \\
\hline \multicolumn{2}{|l|}{ Age } \\
\hline Mean (range) & $55(24-65)$ \\
\hline \multicolumn{2}{|l|}{ Gender } \\
\hline Female & $14(66.7 \%)$ \\
\hline Male & $7(33.3 \%)$ \\
\hline \multicolumn{2}{|c|}{ Classification of Health Professionals } \\
\hline Rural Trainees & $4(19 \%)$ \\
\hline General Practitioners & $7(33.3 \%)$ \\
\hline Family medicine Doctors & $6(28.6 \%)$ \\
\hline Pediatricians & $3(14.3 \%)$ \\
\hline Psychiatrist & $1(4.8 \%)$ \\
\hline Patients & $N(\%)$ \\
\hline Total of patients & $1393(100 \%)$ \\
\hline \multicolumn{2}{|l|}{ Age } \\
\hline Mean (range) & $16(0-93)$ \\
\hline \multicolumn{2}{|l|}{ Age Groups } \\
\hline $0-17$ years & $913(65.5 \%)$ \\
\hline$\geq 18$ years & $480(34.5 \%)$ \\
\hline \multicolumn{2}{|l|}{ Gender } \\
\hline Female & $804(57.7 \%)$ \\
\hline Male & $589(42.3 \%)$ \\
\hline \multicolumn{2}{|l|}{ Antibiotic prescription } \\
\hline \multicolumn{2}{|l|}{$0-17$ years } \\
\hline Yes & 337 (36.9\%) \\
\hline No & $576(63.1 \%)$ \\
\hline \multicolumn{2}{|l|}{$\geq 18$ years } \\
\hline $\begin{array}{l}\text { Yes } \\
\text { No }\end{array}$ & $\begin{array}{l}186(38.75 \%) \\
294(61.25 \%)\end{array}$ \\
\hline
\end{tabular}

of cases were prescribed antibiotics, when none of them needed them. In the case of suppurative and nonspecified otitis media (H66), all of them needed antibiotics and were all accurately prescribed.

Our data includes a classification of all health professionals working at the health center that can prescribe antibiotics. These categories are defined as: General Practitioners, Rural Medical Trainees, Family Medicine Doctors, Pediatricians and Psychiatrists. The results for the analysis of antibiotic prescription depending on the classification of health professionals are shown in Table 6.

Our final multiple logistic regression model included antibiotic prescription as a dependent variable and classification of health professional, sex of prescriber and hours of clinical practice of the health professional as independent variables. We found a statistically significant difference in antibiotic prescription by classification of health professional. We used Family Medicine Doctors as the category of reference for the variable of categories of health professionals. When holding gender of prescriber and hours of clinical practice constant, the odds of antibiotic prescription compare to Family Medicine Doctors was of 4.62 times for Rural Medicine Trainees, 2.58 times for Pediatricians and 1.78 times for General Practitioners. When adjusting for classification of health professional and hours of clinical practice, there was no statistically significant difference in prescription between male and female health professionals (Table 7).

\section{Adequacy of dosage and duration of prescription of antibiotics}

Without regarding appropriateness or adequacy of prescription, we analyzed adequacy of dosage of all antibiotic prescriptions. The average number of days of treatment prescribed was of 7.26 days (range 1-15 days) with a mode of 7 days. The distribution of antibiotic classes used are shown in Fig. 1. 
Table 5 Appropriateness and adequacy of antibiotic prescription according to ICD-10 diagnosis code

\begin{tabular}{|c|c|c|c|c|c|c|}
\hline ICD-10 Code & \# of patients & $\begin{array}{l}\text { Prescribed } \\
\text { Antibiotic }\end{array}$ & $\begin{array}{l}\text { Cases that } \\
\text { needed } \\
\text { antibiotic }\end{array}$ & $\begin{array}{l}\text { Cases that } \\
\text { needed + } \\
\text { received } \\
\text { antibiotics }\end{array}$ & $\begin{array}{l}\text { Appropriate } \\
\text { prescription } \\
\text { rate (\%) }\end{array}$ & $\begin{array}{l}\text { Adequate } \\
\text { prescription } \\
\text { rate (\%) }\end{array}$ \\
\hline J00 & 581 & 17 & 14 & 1 & 82.36 & 7.14 \\
\hline J01 & 93 & 70 & 4 & 4 & 5.71 & 100 \\
\hline$J 02$ & 306 & 157 & 9 & 5 & 3.18 & 2.94 \\
\hline J03 & 166 & 138 & 16 & 15 & 11.59 & 93.75 \\
\hline$J 04$ & 34 & 12 & 0 & 0 & - & - \\
\hline$J 05$ & 8 & 0 & 0 & 0 & - & - \\
\hline$J 06$ & 191 & 117 & 0 & 0 & 0 & 0 \\
\hline J10 & 0 & 0 & 0 & 0 & - & - \\
\hline J11 & 0 & 0 & 0 & 0 & - & - \\
\hline H65 & 8 & 6 & 2 & 2 & 33.33 & 100 \\
\hline H66 & 6 & 6 & 6 & 6 & 100 & 100 \\
\hline Total & 1393 & 523 & 51 & 33 & 9.75 & 64.70 \\
\hline
\end{tabular}

Appropriate and adequate prescription for codes J04, J05, J10, J11 were not estimated. J00 Acute nasopharyngitis [common cold], J01 Acute sinusitis, J02 Acute pharyngitis, $\mathrm{J} 03$ Acute tonsillitis, $\mathrm{J04}$ Acute laryngitis and tracheitis, J05 Acute obstructive laryngitis [croup] and epiglottitis, J06 Acute upper respiratory infections of multiple and unspecified sites, J10 Influenza due to other identified influenza virus, J11 Influenza due to unidentified influenza virus

Out of the 523 patients that received antibiotics, 493 (94.3\%) were prescribed one antibiotic and $30(5.7 \%)$ were prescribed a combination of antibiotics. The two types of combinations prescribed were 'Benzathine penicillin + Amoxicillin' in 26 patients (86.7\%) and 'Benzathine penicillin + Azitromycine’ for 4 patients (13.3\%). Neither one of the combinations of antibiotics used can be considered as appropriate prescription.

Out of the 337 children that were prescribed antibiotics, 7 received a combination of antibiotics, resulting in 344 antibiotics prescribed in children (single or in combination). Considering weight was reported for all the children included in this study, we were able to calculate the adequate dose for treatment in this group of patients.

Amoxicillin was prescribed in 272 (79.06\%) times in children (Fig. 2), of which $6.99 \%$ were prescribed with an adequate dose. Out of all the antibiotics prescribed, $16.86 \%$ were prescribed with an adequate dose, $48.26 \%$ did not reach the adequate dose and $34.88 \%$ went over the adequate dose. The description of adequate doses of each antibiotic prescribed for children can be found in Table 8 with further details in Fig. 2.

Out of the 186 adults that were prescribed antibiotics, 23 received a combination of antibiotics, resulting in 209 antibiotics prescribed in adults. Amoxicillin was prescribed 105 times in adults, all of which were prescribed with an adequate dose. Out of all antibiotics prescribed in adults, 93.30\% were prescribed with an adequate dose, $0 \%$ did not reach the adequate dose and $6.70 \%$ went over the adequate dose. The description for the adequate dose of each antibiotic prescribed for adults can be found in Table 8 with further details in Fig. 2.

Table 6 Appropriateness and adequacy of antibiotic prescription according to health professionals

\begin{tabular}{|c|c|c|c|c|c|c|}
\hline & \# of patients & Prescribed Antibiotic & $\begin{array}{l}\text { Cases that } \\
\text { needed antibiotic }\end{array}$ & $\begin{array}{l}\text { Cases that needed } \\
+ \text { received antibiotics }\end{array}$ & $\begin{array}{l}\text { Appropriate } \\
\text { prescription rate (\%) }\end{array}$ & $\begin{array}{l}\text { Adequate } \\
\text { prescription rate (\%) }\end{array}$ \\
\hline $\begin{array}{l}\text { General Practitioners } \\
(n=7)\end{array}$ & 692 & 226 & 21 & 14 & 9.29 & 66.66 \\
\hline $\begin{array}{l}\text { Family Medicine Doctors } \\
(n=6)\end{array}$ & 128 & 29 & 9 & 5 & 31.03 & 55.55 \\
\hline $\begin{array}{l}\text { Rural Medical Trainees } \\
(n=4)\end{array}$ & 30 & 17 & 2 & 2 & 11.76 & 100 \\
\hline $\begin{array}{l}\text { Psychiatrists } \\
(n=1)\end{array}$ & 23 & 23 & 1 & 1 & 4.34 & 100 \\
\hline $\begin{array}{l}\text { Pediatricians } \\
(n=3)\end{array}$ & 520 & 228 & 18 & 11 & 7.89 & 61.11 \\
\hline Total & 1393 & 523 & 51 & 33 & 9.75 & 64.7 \\
\hline
\end{tabular}


Table 7 Odds Ratios of antibiotic prescription

\begin{tabular}{lll}
\hline Variable & Odds Ratio $(95 \% \mathrm{Cl})$ & $P$-value \\
\hline Category of Health Professional & & \\
Family Medicine Doctor (REF) & 1.00 & \\
Pediatrician & $2.59(1.64-4.08)$ & 0.000 \\
General Practitioner & $1.78(1.14-2.78)$ & 0.012 \\
Rural Trainee & $4.62(2.00-10.67)$ & 0.000 \\
Gender of Prescriber & & \\
Male (REF) & 1.00 & \\
Female & $0.89(0.68-1.18)$ & 0.422 \\
Hours dedicated to clinical practice per day & \\
O (REF) & 1.00 & 0.011 \\
1+ & $1.38(1.08-1.76)$ & \\
\hline
\end{tabular}

REF: Reference category

We then analyzed the number of prescriptions that met the recommended duration of treatment. Out of all the prescriptions, $85.66 \%$ met the recommended duration of antibiotic treatment, $9.37 \%$ were prescribed less than the recommended duration and $4.97 \%$ went over the recommended duration (Table 9).

\section{Discussion}

The results of our study report a $90.25 \%$ of inappropriate prescription in the Health Center that we evaluated. An estimated average of antibiotic prescription appropriateness from studies around the world, mostly including high - middle income countries, is of about $50 \%$ [8, 26-31]. A review of 344 studies between 1990 and 2009 on the treatment of childhood infections in 78 low-middle income countries reported that a high percentage of viral upper respiratory tract infection cases were being treated with antibiotics, with this percentage increasing over time (from $42 \%$ before 1990 up to $72 \%$ in 2006-2009) [32]. This same study reports $47.1 \%$ of inappropriate antibiotic use in URTI in lower-middle income countries and 25.8\% for Latin America.

This means that our study reflects almost one eighth of appropriate prescription as compared to other countries around the world. This astonishing number allows us to realize the amount of work that needs to be done locally to improve this rate.

Studies analyzing the same issue also evaluated the rate of antibiotic prescription and compared their results to a baseline. These studies did not consider if those prescriptions were necessary or not or if the dosage of antibiotics was adequate, but they did calculate the rate of antibiotic prescription that we can compare our study to. Cordoba, et al. [11] published a study in 2016 that evaluated antibiotic prescription in patients with a suspected diagnosis of URTI in primary care health centers in four Latin-American countries. The reported antibiotic prescription rate was of 35\% in Argentina, 40\% in Bolivia, $24 \%$ in Paraguay and $27 \%$ in Uruguay. Another study by Doubova et al. [33] in Mexico reported more than $61 \%$ of children diagnosed with non-streptococcal URTI received antibiotics after the first visit to the health facility. These studies did not evaluate the appropriate prescription rate but show that in a comparable context the rate of antibiotic prescriptions is very similar.

A study about Denmark and Iceland published in 2015 [34] evaluated antibiotic prescription in URTI by general practitioners. The results demonstrate a prescription rate of 59.3\% in Denmark and 75.8\% in Iceland. Appropriate antibiotic prescription was also assessed by analyzing days of symptoms and Centor Criteria, possibly underestimating

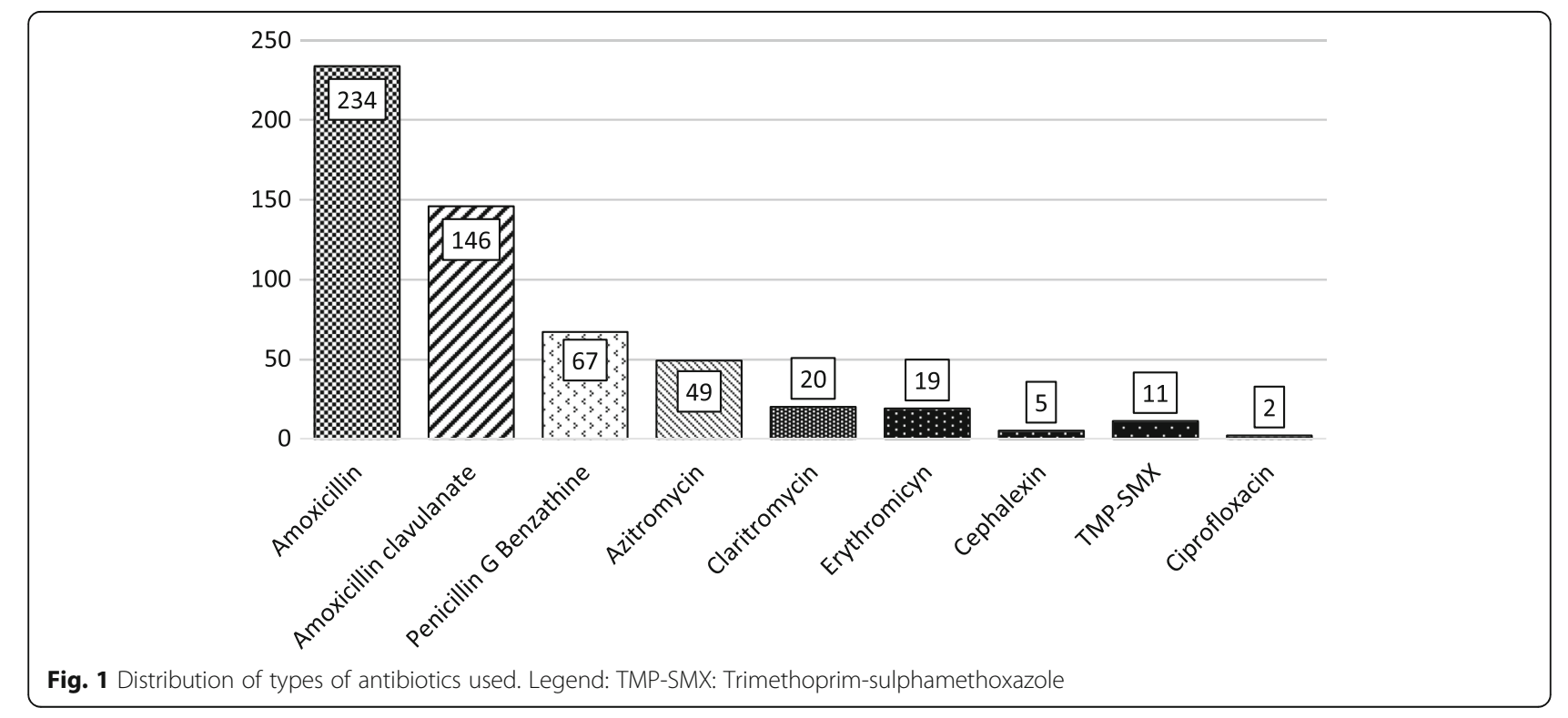




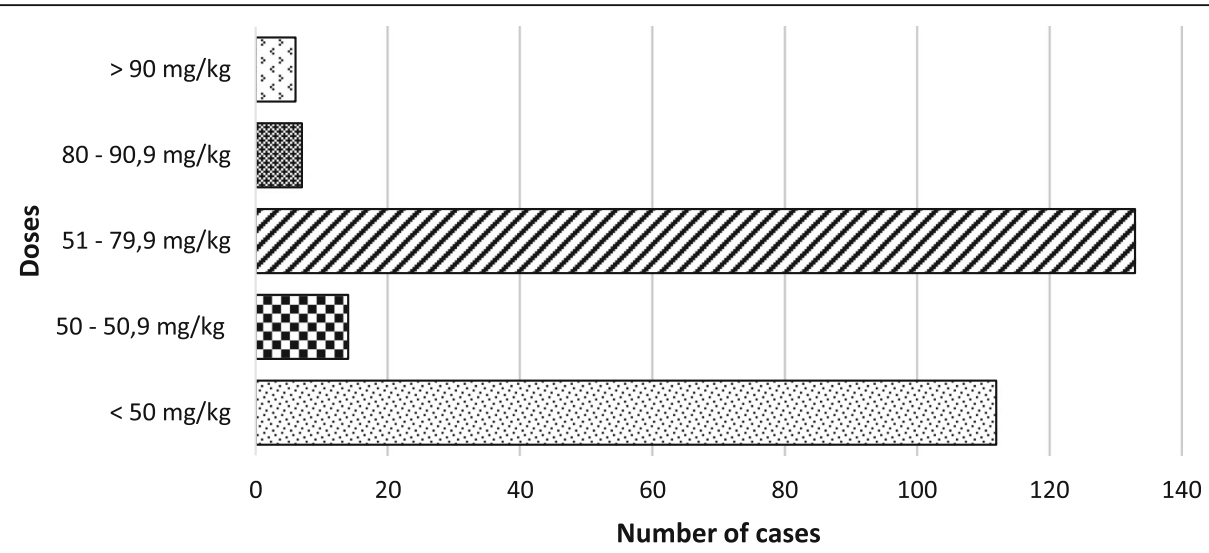

Fig. 2 Amoxicillin used doses in children. Legend: Doses of 50-50.9 mg/kg/day and 80-90.9 mg/kg/day are considered as adequate according to different diagnosis

inappropriate use. Their results show a rate of $16.4 \%$ for sinusitis and 26.3\% for pharyngitis in Denmark and 17.8 and $21.3 \%$ in Iceland. Another study done in 6 countries [35] (Switzerland, Denmark, Argentina, Spain, Russia and Lithuania) reported a $50 \%$ inappropriate prescription rate and close to $100 \%$ inappropriate prescription for rhinopharyngitis and otitis media. These studies show very low appropriate antibiotic prescription rates like the one we found in our study.
It is as important to note the cases of inadequate care, where patients needed antibiotics and did not receive them. Of the total number of cases that required antibiotic prescription, $35.2 \%$ did not receive antibiotics. Considering the $93.7 \%$ of over-prescription, we would recommend further studies to identify the cause of this rate.

When we analyze the data by diagnosis, we see that the antibiotic prescription rate for common cold is very low, as it should be according to the clinical guideline

Table 8 Appropriateness of antibiotic dose

\begin{tabular}{|c|c|c|c|c|}
\hline Antibiotic & Adequate dose & Under adequate dose & Over adequate dose & Total \\
\hline \multicolumn{5}{|l|}{ Pediatric } \\
\hline Amoxicillin (otitis and sinusitis) & $5(9.09 \%)$ & $44(80 \%)$ & $6(10.90 \%)$ & 55 \\
\hline Amoxicillin (other diagnostics) & $14(6.45 \%)$ & $112(51.61 \%)$ & $91(41.93 \%)$ & 217 \\
\hline Azithromycin & $2(18.18 \%)$ & $6(54.54 \%)$ & $3(27.27 \%)$ & 11 \\
\hline Clarithromycin & $6(30 \%)$ & $2(10 \%)$ & $12(60 \%)$ & 20 \\
\hline Erythromycin & $15(83.33 \%)$ & $2(11.11 \%)$ & $1(5.55 \%)$ & 18 \\
\hline Penicillin G Benzathine & $12(70.59 \%)$ & $0(0 \%)$ & $5(29.41 \%)$ & 17 \\
\hline Cephalexine & $2(50 \%)$ & $0(0 \%)$ & $2(50 \%)$ & 4 \\
\hline Trimethoprim-sulphamethoxazole & $2(100 \%)$ & $0(0 \%)$ & $0(0 \%)$ & 2 \\
\hline Total & $58(16.86 \%)$ & $166(48.26 \%)$ & $120(34.88 \%)$ & 344 \\
\hline \multicolumn{5}{|l|}{ Adults } \\
\hline Amoxicillin (otitis and sinusitis) & $20(100 \%)$ & $0(0 \%)$ & $0(0 \%)$ & 20 \\
\hline Amoxicillin (other diagnostics) & 85 (100\%) & $0(0 \%)$ & $0(0 \%)$ & 85 \\
\hline Azithromycin & $37(97.36 \%)$ & $0(0 \%)$ & $1(2.63 \%)$ & 38 \\
\hline Clarithromycin & $3(100 \%)$ & $0(0 \%)$ & $0(0 \%)$ & 3 \\
\hline Erythromycin & $1(100 \%)$ & $0(0 \%)$ & $0(0 \%)$ & 1 \\
\hline Penicillin G Benzathine & $38(76 \%)$ & $0(0 \%)$ & $12(24 \%)$ & 50 \\
\hline Cephalexine & $1(100 \%)$ & $0(0 \%)$ & $0(0 \%)$ & 1 \\
\hline Trimethoprim-sulphamethoxazole & $9(100 \%)$ & $0(0 \%)$ & $0(0 \%)$ & 9 \\
\hline Ciprofloxacin & $1(50 \%)$ & $0(0 \%)$ & $1(50 \%)$ & 2 \\
\hline Total & 195 (93.30\%) & $0(0 \%)$ & $14(6.70 \%)$ & 209 \\
\hline
\end{tabular}


Table 9 Duration of Prescription of Antibiotics

\begin{tabular}{llll}
\hline Antibiotic & $\begin{array}{l}\text { Meets recommended } \\
\text { duration of treatment }\end{array}$ & $\begin{array}{l}\text { Under recommended } \\
\text { duration of treatment }\end{array}$ & $\begin{array}{l}\text { Over recommended } \\
\text { duration of treatment }\end{array}$ \\
\hline $\begin{array}{l}\text { All antibiotics prescribed that have a } \\
\text { recommendation of } 7-10 \text { days of treatment }\end{array}$ & $388(88.79 \%)$ & $24(5.49 \%)$ & $25(5.72 \%)$ \\
$\begin{array}{l}\text { Azithromycin } \\
\text { (Recommendation of } 5 \text { days of treatment) }\end{array}$ & $23(46.94 \%)$ & $25(51.02 \%)$ & $1(2.04 \%)$ \\
$\begin{array}{l}\text { Penicillin G Benzathine } \\
\text { (Recommendation of one single dose) }\end{array}$ & $37(100 \%)$ & $0(0 \%)$ & $0(0 \%)$ \\
Total & $448(85.66 \%)$ & $49(9.37 \%)$ & $26(4.97 \%)$ \\
\hline
\end{tabular}

used to describe appropriateness of prescription for this study. This allows us to see that the common cold is not a major problem of antibiotic prescription in this case. The data shows that with any diagnosis different from a common cold, health professionals at this health center tend to prescribe antibiotics at a much higher rate. There is a particular concern with "acute upper respiratory infections of multiple and unspecified sites" (J06), where the group of identified symptoms can reflect other diagnosis, but are classified in this category that leaves an open diagnosis. In this case, patients received antibiotics at a high rate, where it is not appropriate in any case. It seems that the vague definition of this category allows for a lot of variation in treatment prescribed.

In Ecuador, all Medical graduates must do a year of training in a rural area in order to be able to practice as a General Practitioner. In North America and Europe, the General Practitioner is being replaced by Family Medicine Doctors, but in Ecuador the General Practitioner is still the most common type of doctor. In our study, when classifying by health professions, Family Medicine Doctors have the lowest odds of prescribing antibiotics. This could be due to the additional years of training that are required to fulfill that degree, giving them the necessary tools to act. The clinical guideline used in this study does not take into consideration psychiatric comorbidities as a parameter for prescription. Even though psychiatric patients tend to have associated comorbidities that are not considered in this study, patients in primary care health centers usually do not have severe psychiatric disorders that could justify an antibiotic prescription due uniquely to their psychiatric condition.

A study by Del Fiol et al. [36], that analyzes the use of antibiotics in children in two Health Centers in Brazil, reports that $50 \%$ of the prescribed dosages of amoxicillin are under the recommended amounts according to Brazilian guidelines. These results are similar to those in our study that show $57.35 \%$ of prescriptions were under the recommended dose for the same antibiotic in children.

One of the most relevant limitations in our study is the fact that we relied on retrospective information from EHR. The EHR used in this district allows for registration of all possible variables, but health professionals in many occasions fill in only what is relevant to them about the current reason of consultation, leading to possible incomplete records. Even though during the consultation the health professional may not include the patients' medical history, like history of prematurity, previous hospitalization and some comorbidities, they are able to find this information in the records and can refer to them in order to decide on diagnosis and treatment. This thought process is not contemplated in our analysis, turning it into a limitation for our study and a possible underestimation of appropriate prescription in some cases. Nevertheless, all the variables described in the clinical guidelines were both registered in all patients included and considered for analysis.

Another limitation is the lack of a National Clinical Guideline for upper respiratory tract infections, forcing us to use the NICE guideline. NICE Guidelines consider a global context, instead of only local studies, for their recommendations, which is why we considered this guideline to be appropriate for our study. Ecuador's Minister of Health recommends the use of international guidelines when there is no local guideline provided. NICE guidelines are always taken into consideration when developing national guidelines in Ecuador, which is why we chose this as our reference.

Another limitation to our study is that the sample comes from only one health center. This is due to the lack of an EHR that can report the included variables for each patient, which led to having to extract all the data manually.

Finding a difference both between health professionals in the amount of antibiotics each prescribe can be helpful when targeting individuals for educational plans about antibiotics. If these variables were analyzed in each health center, the specific health professionals that need educational interventions about the appropriate use of antibiotics can be targeted.

\section{Conclusion}

In the health center in Ecuador included in the study there is a high rate of inappropriate prescribing of antibiotics; these findings support the need for implementation of strategies to reduce the prescription of antibiotics. Creating this 
baseline for the whole country instead of one health center could be the first step to realizing the scope of the problem in Ecuador. The antibiotic prescription, appropriate prescription and adequate prescription rates all underscore the need for further research and specific policy analysis and implementation in developing countries. Knowing that inadequate antibiotic prescribing is a problem in this local setting can contribute to an appropriate prescription policy.

\section{Additional files}

Additional file 1: "Description of Variables", shows variables collected for the analysis of appropriateness and adequacy of antibiotic prescription. (DOCX $23 \mathrm{~kb}$ )

Additional file 2: "Variables considered for the regression model", shows variables chosen for bivariate logistic regression model. (DOCX $21 \mathrm{~kb}$ )

\section{Abbreviations}

EHR: Electronic Health Records; ICD: International Classification of Disease; NICE: National Institute for Health and Care Excellence; URTI: Upper Respiratory Tract Infection; WHO: World Health Organization

\section{Acknowledgments}

We thank those who facilitated the collection of data, i.e., the head authorities, local administration authorities and health authorities from the Ministry of Public Health. We also thank all the staff from the Health District $17 D 03$ of Quito for support during field work.

\section{Funding}

There is no funding.

\section{Availability of data and materials}

The datasets used and/or analyzed during the current study are available from the corresponding author on reasonable request.

\section{Authors' contributions}

$\mathrm{XS}$ and RJ designed the study and participated in the elaboration of the protocol, LA and XS analyzed results and wrote the manuscript; LA participated in statistical analysis and wrote the manuscript; XS and RJ participated in fields and bench work; LA corrected manuscript. All authors read and approved the final manuscript.

\section{Ethics approval and consent to participate}

The study was approved by the Committee for Research Ethics on Human Beings - PUCE (authorization CEISH-222-2016, 09th November 2016).

\section{Consent for publication}

Not applicable.

\section{Competing interests}

The authors declare that they have no competing interest.

\section{Publisher's Note}

Springer Nature remains neutral with regard to jurisdictional claims in published maps and institutional affiliations.

Received: 5 October 2017 Accepted: 13 July 2018

Published online: 27 July 2018

\section{References}

1. Promoting Rational Use of Medicines: Core Components - WHO Policy Perspectives on Medicines, No. 005, 2002. [cited 2017 Feb 17]. Available from: http://apps.who.int/medicinedocs/en/d/Jh3011e/
2. The World Medicines Situation: Chapter 7. Access to essential medicines. [cited 2017 Nov 15]. Available from: http://apps.who.int/medicinedocs/es/d/ Js6160e/9.html

3. WHO | Rational use of medicines. WHO. [cited 2018 Jan 25]. Available from: http://www.who.int/medicines/areas/rational_use/en/

4. Guide to Good Prescribing - A Practical Manual. [cited 2017 Nov 15] Available from: http://apps.who.int/medicinedocs/en/d/Jwhozip23e/

5. Morgan SG, Weymann D, Pratt B, Smolina K, Gladstone EJ, Raymond C, et al. Sex differences in the risk of receiving potentially inappropriate prescriptions among older adults. Age Ageing. 2016;(May):afw074.

6. Lopez-Vazquez P, Vazquez-Lago JM, Figueiras A. Misprescription of antibiotics in primary care: a critical systematic review of its determinants. J Eval Clin Pract. 2012;18(2):473-84

7. Voigt K, Gottschall M, Köberlein-Neu J, Schübel J, Quint N, Bergmann A, et al. Why do family doctors prescribe potentially inappropriate medication to elderly patients? BMC Fam Pract. 2016;17(1):93.

8. Fleming-Dutra KE, Hersh AL, Shapiro DJ, Bartoces M, Enns EA, File TM, et al. Prevalence of inappropriate antibiotic prescriptions among US ambulatory care visits, 2010-2011. JAMA. 2016 May 3;315(17):1864-73.

9. Al-Tawfiq JA, Alawami AH. A multifaceted approach to decrease inappropriate antibiotic use in a pediatric outpatient clinic. Ann Thorac Med. 2017 Jan 1;12(1):51.

10. Butler CC, Hood K, Verheij T, Little P, Melbye H, Nuttall J, et al. Variation in antibiotic prescribing and its impact on recovery in patients with acute cough in primary care: prospective study in 13 countries. BMJ. 2009;338:b2242.

11. Cordoba G, Caballero L, Sandholdt H, Arteaga F, Olinisky M, Ruschel LF, et al. Antibiotic prescriptions for suspected respiratory tract infection in primary care in South America. J Antimicrob Chemother. 2017;72(1):305-10.

12. OMS / Resistencia a los antimicrobianos. WHO. 2015:

13. Word Health Organization (WHO). WHO Global Strategy for Containment of Antimicrobial Resistance WHO Global Strategy for Containment of Antimicrobial Resistance World Health Organization 2001.

14. Costelloe C, Metcalfe C, Lovering A, Mant D, Hay AD. Effect of antibiotic prescribing in primary care on antimicrobial resistance in individual patients: systematic review and meta-analysis. BMJ. 2010;340:c2096.

15. Cosgrove SE. The relationship between antimicrobial resistance and patient outcomes: mortality, length of hospital stay, and health care costs. Clin Infect Dis. 2006:42(Supplement_2):S82-9.

16. Word Health Organization. Antimicrobial resistance. WHO. In: World Health Organization; 2017.

17. Butt AA, Navasero CS, Thomas B, Marri SA, Katheeri HA, Thani AA, et al. Antibiotic prescription patterns for upper respiratory tract infections in the outpatient Qatari population in the private sector. Int J Infect Dis IJID Off Publ Int Soc Infect Dis 2017:55:20-23.

18. Dekker ARJ, Verheij TJM, van der Velden AW. Inappropriate antibiotic prescription for respiratory tract indications: most prominent in adult patients. Fam Pract. 2015;32(4):401-7.

19. Kotwani A, Holloway K. Antibiotic prescribing practice for acute, uncomplicated respiratory tract infections in primary care settings in New Delhi, India. Trop Med Int Health TM IH. 2014;19(7):761-8.

20. Shulman ST, Bisno AL, Clegg HW, Gerber MA, Kaplan EL, Lee G, et al. Clinical practice guideline for the diagnosis and management of group a streptococcal pharyngitis: 2012 update by the Infectious Diseases Society of America. Clin Infect Dis Off Publ Infect Dis Soc Am. 2012;55(10):1279-82.

21. Harris AM, Hicks LA, Qaseem A. High value care task force of the American College of Physicians and for the Centers for Disease Control and Prevention. Appropriate antibiotic use for acute respiratory tract infection in adults: advice for high-value care from the American College of Physicians and the Centers for Disease Control and Prevention. Ann Intern Med. 2016; 164(6):425-34

22. Lieberthal AS, Carroll AE, Chonmaitree T, Ganiats TG, Hoberman A, Jackson MA, et al. The diagnosis and management of acute otitis media. Pediatrics. 2013;131(3):e964-99.

23. Chow AW, Benninger MS, Brook I, Brozek JL, Goldstein EJC, Hicks LA, et al. Executive summary: IDSA clinical practice guideline for acute bacterial Rhinosinusitis in children and adults. Clin Infect Dis. 2012:54(8):1041-5.

24. SECRETARIA DE SALUD. Diagnóstico y manejo de la infección aguda de vías aéreas superiores en pacientes mayores de 3 meses hasta 18 años de eda. 2016 [cited 2018 Apr 5]. Available from: http://www.cenetec.salud.gob.mx/ descargas/gpc/CatalogoMaestro/062 GPC InfAgVASde3mesesa18a/ INFECCION_VIAS_AEREAS_EVR_CENETEC.pdf 
25. SECRETARIA DE SALUD DE MEXICO. Diagnóstico y Tratamiento de Faringoamigdalitis Aguda. 2009 [cited 2018 Apr 5]. Available from: http:// www.cenetec.salud.gob.mx/descargas/gpc/CatalogoMaestro/073_GPC_ Faringoamgaguda/Faringo_ER_CENETEC.pdf

26. Shamsuddin S, Akkawi ME, Zaidi STR, Ming LC, Manan MM. Antimicrobial drug use in primary healthcare clinics: a retrospective evaluation. Int J Infect Dis. 2016 Nov 1;52:16-22.

27. Butt AA, Navasero CS, Thomas B, Marri SA, Katheeri HA, Thani AA, et al. Antibiotic prescription patterns for upper respiratory tract infections in the outpatient Qatari population in the private sector. Int J Infect Dis. 2017:55:20-3

28. Dekker ARJ, Verheij TJM, van der Velden AW. Inappropriate antibiotic prescription for respiratory tract indications: most prominent in adult patients. Fam Pract. 2015 Aug;32(4):401-7.

29. Gill JM, Fleischut P, Haas S, Pellini B, Crawford A, Nash DB. Use of antibiotics for adult upper respiratory infections in outpatient settings: a national ambulatory network study. Fam Med. 2006;38(5):349-54.

30. Kourlaba G, Gkrania-Klotsas E, Kourkouni E, Mavrogeorgos G, Zaoutis TE. Antibiotic prescribing and expenditures in outpatient adults in Greece, 2010 to 2013: evidence from real-world practice. Euro Surveill Bull Eur Sur Mal Transm Eur Commun Dis Bull. 2016;21(26)

31. Shapiro DJ, Hicks LA, Pavia AT, Hersh AL. Antibiotic prescribing for adults in ambulatory care in the USA, 2007-09. J Antimicrob Chemother. 2014;69(1):234-40.

32. Holloway KA, Ivanovska V, Wagner AK, Vialle-Valentin C, Ross-Degnan D. Prescribing for acute childhood infections in developing and transitional countries, 1990-2009. Paediatr Int Child Health. 2015;35(1):5-13.

33. Doubova SV, Perez-Cuevas R, Balandrán-Duarte DA, Rendón-Macías ME. Quality of care for children with upper respiratory infections at Mexican family medicine clinics. Bol Méd Hosp Infant México. 2015;72(4):235-41.

34. Rún Sigurðardóttir N, Nielsen ABS, Munck A, Bjerrum L. Appropriateness of antibiotic prescribing for upper respiratory tract infections in general practice: comparison between Denmark and Iceland. Scand J Prim Health Care. 2015;33(4):269-74.

35. Bagger K, Nielsen ABS, Siersma V, Bjerrum L. Inappropriate antibiotic prescribing and demand for antibiotics in patients with upper respiratory tract infections is hardly different in female versus male patients as seen in primary care. Eur J Gen Pract. 2015;21(2):118-23.

36. Del Fiol Fde S, Lopes LC, Barberato-Filho S, de CB MC. Evaluation of the prescription and use of antibiotics in Brazilian children. Braz I Infect Dis Off Publ Braz Soc Infect Dis. 2013;17(3):332-7.

Ready to submit your research? Choose BMC and benefit from:

- fast, convenient online submission

- thorough peer review by experienced researchers in your field

- rapid publication on acceptance

- support for research data, including large and complex data types

- gold Open Access which fosters wider collaboration and increased citations

- maximum visibility for your research: over $100 \mathrm{M}$ website views per year

At $\mathrm{BMC}$, research is always in progress.

Learn more biomedcentral.com/submissions 